\title{
Auditory Hallucinations: A Phenomenological Study
}

\author{
Gaurav Verma', Mehul Brahmbhatt ${ }^{2}$, Ganpat Kodarbhai Vankar ${ }^{3}$, Minakshi Nimesh Parikh ${ }^{4}$ \\ ${ }^{1}$ Assistant Professor, Department of Psychiatry, Varun Arjun Medical College, Banthra, Shahjahanpur, Uttar Pradesh, \\ India, ${ }^{2}$ Associate Professor, ${ }^{4}$ Professor, Department of Psychiatry, B.J. Medical College, Ahmedabad, Gujarat, India, \\ ${ }^{3}$ Professor, Department of Psychiatry, Parul Institute of Medical Sciences and Research, Vadodara, Gujarat, India
}

Background: Auditory hallucinations are common feature in psychotic disorder and have also given diagnostic importance. These hallucinations can be rated on different dimensions both quantitatively and qualitatively, so here comes phenomenological aspect. Study of phenomenological aspects may lead to more understanding about them and further can help in management of distressing auditory hallucinations. Aims and Objectives: The aims and objectives of the current study was as follows- 1 . To explore the phenomenology of auditory hallucination in schizophrenia spectrum disorder. 2. To find out clinical correlation of auditory hallucination with other psychotic symptoms. 3. To find out factor structure of PSYRATS (Psychotic Symptom Rating Scale) and their correlation with PANSS and its subscales. Materials and Methods: One hundred patients, who had schizophrenia spectrum diagnoses attending general hospital psychiatry unit in India having auditory verbal hallucination (AVH) in last seven days were studied. Phenomenology was assessed by using Psychotic Symptoms Rating Scale (PSYRATS) and Positive and Negative Syndrome Scale (PANSS). Pearson correlation for the psychotic symptoms, Dimensions of psychotic symptoms on PSYRATS were explored by principal component analysis. Results: In study $82 \%$ patients had schizophrenia. More than one third patients heard voices continuously, in more than two-third patients voices were coming from outside head only, had no control over them, and had same loudness as one's own voice. One third patients had AVH (Auditory Verbal Hallucinations) with all negative content, $19 \%$ had AVH commanding nature. $79 \%$ had delusions, $96 \%$ had hallucinatory behavior. Bipolar index showed dominance of positive symptoms. $80 \%$ reported depression. On principal component analysis three factors found, all three factors were positively correlated with positive subscale and total PANSS score. None of three factors were correlated with negative subscale of PANSS. Conclusion: In this study of $\mathrm{AVH}$ phenomenology among schizophrenia spectrum disorders, most dimensions of $\mathrm{AVH}$ correlated well with one another. On principal component analysis three factor structure of PSYRATS was found.

Key words: Auditory hallucinations; Schizophrenia spectrum disorders
http://nepjol.info/index.php/AJMS DOI: 10.3126/ajms.v12i5.34011

E-ISSN: 2091-0576

P-ISSN: 2467-9100

Copyright (c) 2021 Asian Journal of Medical Sciences

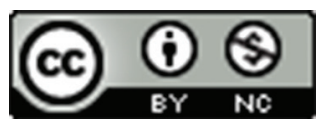

This work is licensed under a Creative Commons Attribution-NonCommercial 4.0 International License.

\section{INTRODUCTION}

Auditory hallucinations are common feature of psychotic illnesses. The diagnosis of schizophrenia is entirely dependent on its cluster or phenomenology and there lies the importance of study the disease from this angle. Hallucination can be analyzed according to their form and content. A hallucination is the perceptual experience that exists in time and space and relates affectively cognitively to present and past experience. The form elements reflect present and perceptual experience, perceived as objective reality. The content of hallucination focuses on patient's life experiences synthesized through memory. The classical teaching proposes a discrimination of form from content in explication of phenomenology. There are conflicting observations in literature regarding both form and content of hallucination. Phenomenology may provide clues to mechanism and pathogenesis of hallucinations. Persistent 
and refractory hallucinations are an important source of morbidity. A phenomenological enquiry that includes the common coping strategies of hallucinating patient may have therapeutic implications. There are many excellent studies published in this area assessing the different dimensions of AVH. ${ }^{1-4}$

\section{Aims and objectives}

- To explore phenomenology of auditory hallucination in schizophrenia spectrum disorders.

- To find out clinical correlation of auditory hallucination with other psychotic symptoms.

- To find out factor structure of PSYRATS (Psychotic Symptom Rating Scale) and their correlations with PANSS and its subscales.

\section{MATERIALS AND METHODS}

\section{Setting and duration}

The study was conducted at a medical school affiliated general hospital in Western India between september2014 to july2015.

\section{Sample size}

One hundred patients of schizophrenia spectrum diagnoses (schizophrenia, schizoaffective disorder, schizophreniform disorder, brief psychotic disorder, psychotic not otherwise specified) were included (DSM-IV TR). ${ }^{5}$

\section{Inclusion criteria}

Diagnosed cases of schizophrenia spectrum psychoses, reporting auditory verbal hallucination, able to provide informed written consent and willing to participate in study were included.

\section{Exclusion criteria}

Patients with co-morbid substance abuse disorder, organic disorder and primary mood disorder, or having severe cognitive deficit that would prohibit the person to participate in interview.

\section{Methodology}

Written informed consent was taken from all participants, socio-demographic data was collected by semi-structured interview with patients and their relatives.

Phenomenology of auditory hallucination and its correlation with other dimensions of psychosis were assessed by using two questionnaires.

1. Psychotic Symptoms Rating Scale (PSYRATS): (Carter, Mackinnon, Howard, Zeegers, Copolov,1995)

It was designed to be more easily administered than lengthy hallucination interviews. It is structured interview, examines 11 auditory hallucinations (PSYRATS-AH) and 6 delusion dimensions. 11 dimensions of Auditory Verbal Hallucination (AVH) are frequency, duration, location (inside head or external), loudness, conviction in belief regarding origin, amount of negative content, degree of negative content, amount of distress, intensity of distress, disruption to life and controllability of voices. Delusion subscale comprises of, amount and duration of preoccupation, conviction, amount and intensity of distress, disruption of life caused by belief. Ratings are done from 0-4, higher rating indicates more severity. Reliability statistics indicated strong inter-rater reliability of PSYRATS-AH (0.79) and adequate test-retest reliability. ${ }^{1}$ Haddock et al. considered that dimensions measured by items were largely independent and found few significant correlations between items. ${ }^{6}$ However, a more recent study has suggested it to be more internally consistent.

2. Positive and Negative Syndrome Scale (PANSS), (Kay et al. $)^{7}$

It is 30 items scale. 7 items constitute a positive scale, 7 items a negative scale and remaining 16 items a general psychopathology scale. The score for these scales is arrived at by summation of ratings across component items. Therefore, the potential ranges are 7 to 49 for the positive and negative scale, and 16 to 112 for the general psychopathology scale. In addition to these measures, a composite scale is scored by subtracting the negative score from positive score. This yield a bipolar index range from -42 to +42 , which is essentially a difference score reflecting the degree of predominance of one syndrome in relation to other. The validity and reliability of PANSS has shown in many studies, Interrated reliability is 0.80 (Kay, Opler, Lindemayer, 1988). ${ }^{8}$

\section{Analysis}

- Done by using SPSS (Statistical Package for Social Sciences, 1996) version 17.'

- Bivariate correlation (Pearson Correlation) was calculated for different dimensions of PSYRATS and PANSS.

- Principal component analysis was done on PSYRATS.

\section{RESULTS}

\section{Demographic characteristics}

Patients age range was 16 to 68 years (Mean 39.68, SD $10.79)$, predominant were male $(68 \%)$, married $(64 \%)$, belongs to Hindu religion (91\%), nuclear family (80\%), urban area $(64 \%)$. Only $9 \%$ patients had graduate or postgraduate degree. The most common diagnosis was schizophrenia $(82 \%)$ [Table 1]. 
The descriptive features of auditory hallucinations is depicted in Table 2.

Seventy-two percent with AVH have abnormal belief, $29 \%$ had severe disruption to life due to belief and hospitalization was usually necessary. Patients reported continuous hearing of voices $(47 \%)$, coming outside head only $(73 \%)$, of same loudness as his/her own $(70 \%) .53 \%$ had $100 \%$ conviction that voices solely due to external causes. Patients reported all voices content was negative and unpleasant $(35 \%)$, command to harm self or others $(19 \%)$, majority of voices were distressing $(23 \%)$, extremely distressing (intensity of distress), felt the worst he/she could possibly feel $(12 \%)$, causes severe disruption of life so that hospitalization was usually necessary $(37 \%)$. Nine percent patients reported that voices caused complete disruption of daily life, requiring hospitalization. The patients were unable to maintain any daily activities and social relationship, self-care also severely disrupted. $71 \%$ admitted that they had no control over their voices.

Persons who had AVH also have hallucinatory behavior $(96 \%)$, suspiciousness $(85 \%)$ and hostility $(46 \%)$. Most of patients had blunted affect (93\%), emotional withdrawal $(89 \%)$, apathetic social withdrawal $(90 \%)$ and stereotyped thinking $(71 \%)$ [Table 3].

Bipolar index showed predominance of positive symptoms $(61 \%)$ over negative symptoms (35\%). Most of patients reported somatic concern $(72 \%)$, anxiety $(73 \%)$, tension $(67 \%)$, unusual thought content $(72 \%)$, lack of judgment and insight (78\%) and preoccupation (76\%). $80 \%$ patients reported depression and $93 \%$ patients had active social avoidance.

The correlation between different dimensions of PSYRATS is shown in Table 4.

The principal component analysis of PSYRATS is shown in Table 5.

The screen plot of eigen value showing two major factors is shown in Figure 1.

The rotated component matrix is shown in Table 6.

On principal component analysis three factors extracted whose eigen value was greater than unity and named as F1(delusion), F2 (influence), F3 (externality). These factors captured $76 \%$ of total variance. On drawing scree plot two major factors were found i.e F1 \& F2 [Figure 1].

F1 named as delusional factor comprises frequency, duration, disruption to life caused by voices and all six

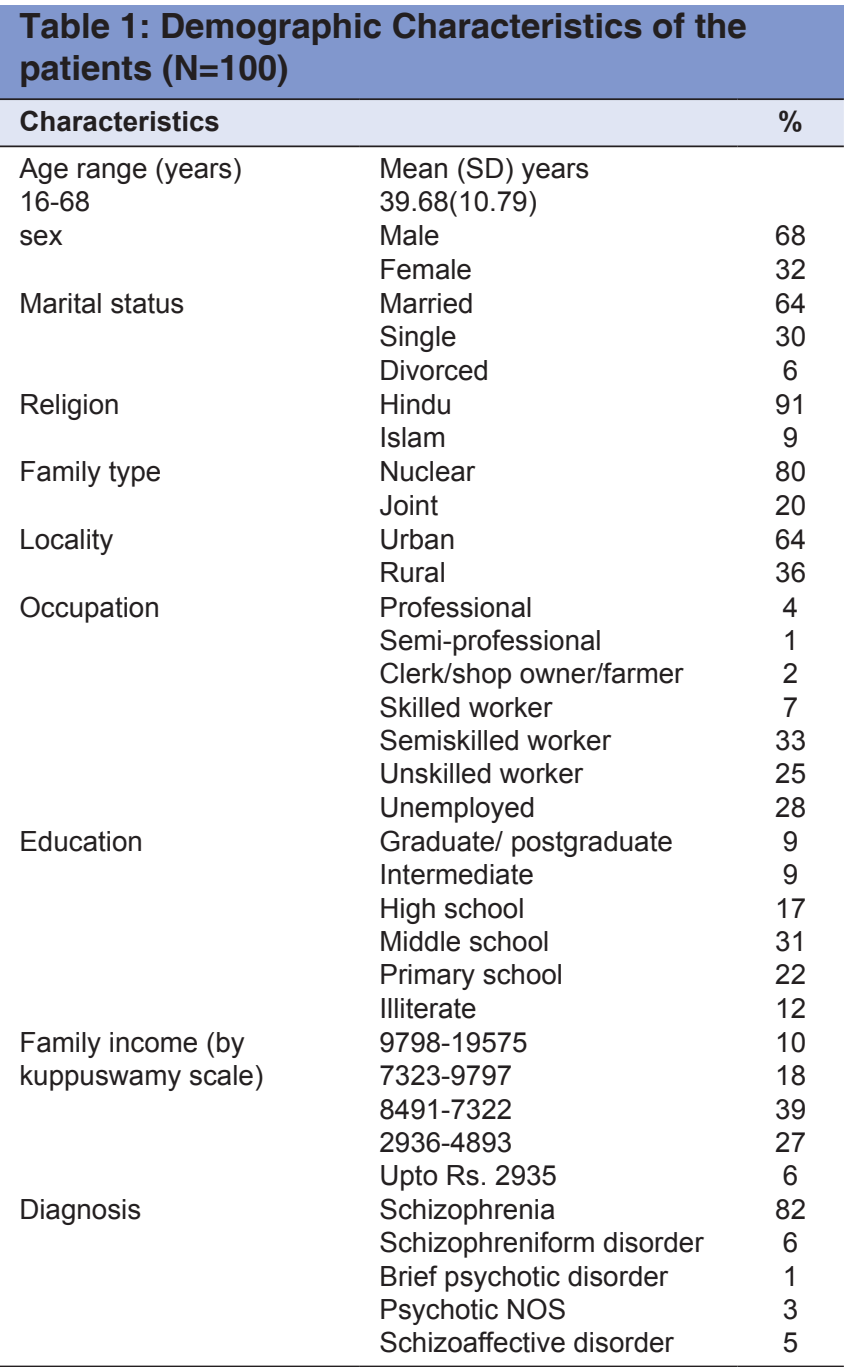

\begin{tabular}{|c|c|c|c|c|c|}
\hline \multirow[t]{2}{*}{ PSYRATS } & \multicolumn{5}{|c|}{$\%$} \\
\hline & 0 & 1 & 2 & 3 & 4 \\
\hline Frequency & 1 & 9 & 21 & 32 & 37 \\
\hline Duration & 0 & 10 & 19 & 24 & 47 \\
\hline Location & 0 & 6 & 2 & 19 & 73 \\
\hline Loudness & 0 & 8 & 70 & 18 & 14 \\
\hline Belief regarding origin of voices & 0 & 4 & 13 & 30 & 53 \\
\hline Amount of negative content of voices & 17 & 5 & 20 & 23 & 35 \\
\hline Degree of negative content & 18 & 16 & 14 & 33 & 19 \\
\hline Amount of distress & 9 & 11 & 14 & 43 & 23 \\
\hline Intensity of distress & 8 & 15 & 29 & 36 & 12 \\
\hline Disruption to life caused by voices & 9 & 11 & 34 & 37 & 9 \\
\hline Controllability of voices & 0 & 5 & 4 & 20 & 71 \\
\hline \multicolumn{6}{|c|}{ DELUSION: $72 \%$ having abnormal belief associated with $\mathrm{AH}$ ) } \\
\hline Amount of preoccupation with delusion & 29 & 7 & 5 & 14 & 45 \\
\hline Duration of preoccupation & 26 & 2 & 11 & 13 & 48 \\
\hline Conviction & 25 & 2 & 22 & 18 & 33 \\
\hline Amount of distress & 25 & 8 & 22 & 23 & 22 \\
\hline Intensity of distress & 25 & 12 & 25 & 27 & 11 \\
\hline Disruption to life & 24 & 15 & 23 & 29 & 7 \\
\hline
\end{tabular}




\section{Table 3: Relationship of AVH with other psychotic features}

\begin{tabular}{lcl}
\hline Positive symptoms PANSS & $\%$ & Negative Symptoms PANSS \\
\hline Delusion & 79 & Blunted affect \\
Conceptual disorganization & 82 & Emotional withdrawal \\
Hallucinatory behavior & 96 & Poor rapport \\
Excitement & 72 & Apathetic social withdrawal \\
Grandiosity & 34 & Difficulty in abstract thinking \\
Suspiciousness/persecution & 85 & Lack of spontaneous flow of conversation \\
Hostility & 46 & Stereotyped thinking \\
\hline & General Psychopathology PANSS \\
\hline Somatic concern & 72 & Unusual thought content \\
Anxiety & 73 & Disorientation\# \\
Guilt feeling & 13 & Poor attention \\
Tension & 67 & Lack of judgment and insight \\
Mannerism \&posturing & 5 & Disturbance of volition \\
Depression & 80 & Poor impulse control \\
Motor retardation & 65 & Preoccupation \\
Uncooperativeness & 26 & Active social avoidance \\
\hline
\end{tabular}

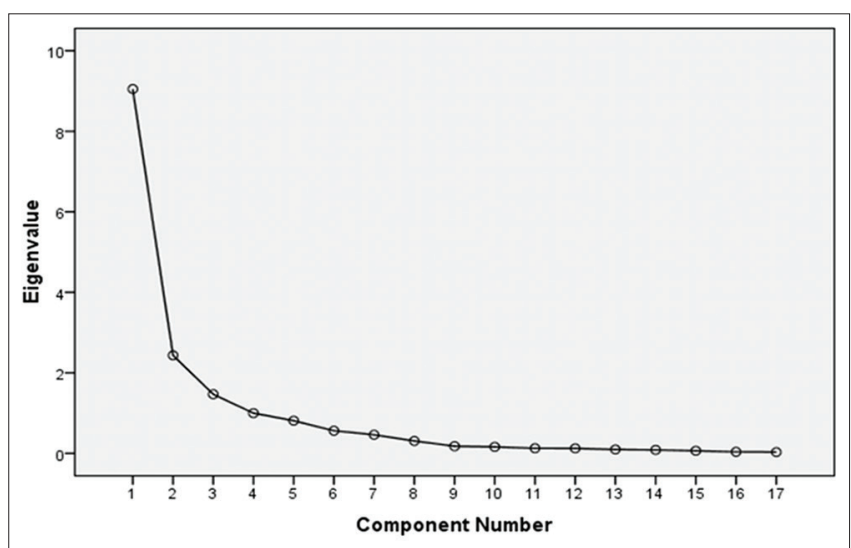

Figure 1: Screen plot of eigen value

components of delusional subscale of PSYRATS. F2 named as influence factor includes loudness of voices, amount and degree of negative content, amount and intensity of distress and disruption of life caused by voices. F3 named as externality factor includes location of voices, belief regarding origin of voices and controllability of voices.

\section{DISCUSSION}

\section{Demographic profile}

All patient with AVH had age range of 16-68 years (Mean 39.68, SD 10.79) which is close to McCarthy-Jones et al study. ${ }^{3} 68 \%$ were male and $32 \%$ were female, which is around similar sex ratio as in Singh et al study. ${ }^{4}$ More than half of patients were married $(63 \%)$ and belonged to Hindu religion (91\%), urban $(60 \%)$, nuclear $(80 \%)$ family. One third patients were educated up to middle school. The most common diagnosis was schizophrenia $(82 \%)$ which was also close to McCarthy-Jones et al. study $(80.9 \%)^{3}$

\section{Phenomenology of AVH}

\section{Frequency, Duration, Location, Loudness}

Auditory hallucinations are the most common hallucinations found in schizophrenic patient. Around 61\% patients with schizophrenia reported auditory hallucinations and 50\% from outer space and most of voices spoke in normal conversational tone. ${ }^{10}$ According to Lewis, et al. $70 \%$ schizophrenic patients have auditory hallucinations. ${ }^{11}$ In our study patients who had auditory verbal hallucination were included in which $37 \%$ were hearing the voices continuously, $47 \%$ had voice lasted for hours at a time (vs $59 \%$ in McCarthy-Jones et al.) $)^{3}, 73 \%$ had voices sound like they are from outside head only (vs 49\% in Nayani and David, et al study), ${ }^{2} 70 \%$ had same loudness of voices as their own voice (vs $73 \%$ Nayani and David et al). ${ }^{2} 18 \%$ had voices louder than own voice (vs 29\% S.McCarthy-jones et al.). ${ }^{3}$ Traditionally, voices perceived as originating outside of head have been given greater emphasis in diagnosis. It may be that the important characteristics of voices perceived as outside the head is not their location but rather the patient's delusional attribute that they are alien. There is no firm evidence that the perception of external voices is somewhat more pathological or indicative of a particular class of disorder. ${ }^{12}$ In Nayani et al. study the internal or external did not differ on reality score. ${ }^{2}$

The neurological literature suggests that experience of unilateral hallucination is associated with contralateral temporal lobe diseases (Almedia et al. 1993) ${ }^{13}$ or with ipsilateral ear discharge (Taylor and Fleminger,1981). ${ }^{14}$

Loudness has high correlation with all other dimensions (including disruption to life) used in PSYRATS except location and controllability of voices. In one study loudness of voices was not correlated with significant interference in patient behavior. ${ }^{15}$ Nayani et al. also showed that frequency was significantly correlated with duration, and total 


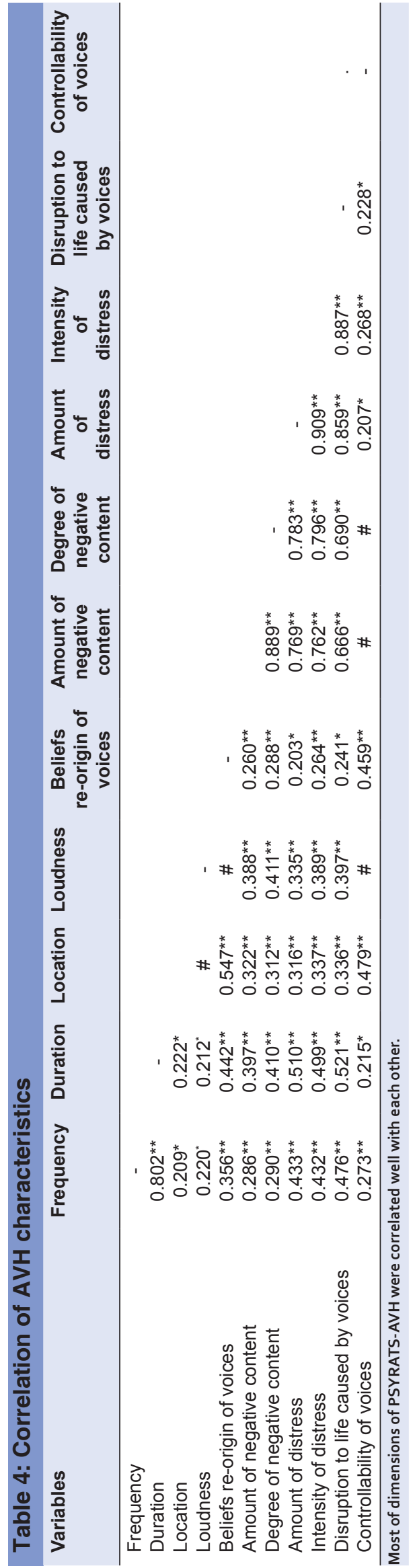

number of recorded words. ${ }^{2}$ As time pass, most of patients experienced a decrease in frequency of their hallucination or change in nature of their hallucinatory experience. ${ }^{11}$

\section{Beliefs regarding origin of voices}

There is a powerful explanation for the belief in external sources of hallucinations by person experiencing them is that no one would want to generate such an experience, the hallucination is usually so unpleasant, so intrusive that it makes no sense that it would arise from within the person who experiences it. ${ }^{11}$

In our study $53 \%$ patients believed that voices were solely due to external causes $(100 \%$ conviction). There was significantly high correlation between location of voices and belief regarding origin of voices (0.547).

\section{Amount of negative content}

Content of auditory hallucinations is more likely to be threatening, antagonistic and isolating during acute psychoses but more likely to be helpful friendly and socially focused during remission. ${ }^{16}$ Person afflicted often hears middle-aged voices with a different accent than is spoken by the patient. Younger patients tend to hear somewhat younger voices, while older patient hear somewhat older voices. ${ }^{11}$ Although there have been decades of speculation about why the content of auditory hallucination is so often threatening or demeaning, there is at present no clear explanation for the generally negative content of auditory hallucination.

In this study $83 \%$ had voices of negative content (vs $60 \%$ McCarthy et al.) $)^{3}, 35 \%$ voices had unpleasant or negative content.

\section{Degree of negative content}

Most of patients with AVH in schizophrenia reported negative content which comprises personal verbal abuse, threat to harm self and command to harm others. Hayashi et al. also showing that negative content, negative patient response, and uncontrollability of voices significantly correlated with depression. ${ }^{17}$

This study showing that depression is found in $80 \%$ of patient with AVH. 33\% had voices of personal verbal abuse, $19 \%$ had voices personal threat to self, including command to harm self and others (vs 35\% command hallucination in MacCarthy-Jones et al). ${ }^{3}$ The presence of command hallucination is associated with "danger related events" in patients units. ${ }^{18}$ However Goodwin et al. reported that patients usually ignore command hallucinations. ${ }^{19}$ In a study of outpatients with schizophrenia, command hallucinations were found in significant number of patients, in most cases they had minimal influence on the outcome of schizophrenia. ${ }^{20}$ 


\section{Table 5: Principal component analysis of PSYRATS}

PSYRATS: Total variance explained

\begin{tabular}{|c|c|c|c|c|c|c|}
\hline \multirow[t]{2}{*}{ Component } & \multicolumn{3}{|c|}{ Initial eigenvalues } & \multicolumn{3}{|c|}{ Rotation sums of squared loadings } \\
\hline & Total & $\%$ of Variance & Cumulative $\%$ & Total & $\%$ of Variance & Cumulative $\%$ \\
\hline 1 & 9.049 & 53.232 & 53.232 & 6.244 & 36.727 & 36.727 \\
\hline 2 & 2.434 & 14.320 & 67.551 & 4.546 & 26.742 & 63.469 \\
\hline 3 & 1.469 & 8.640 & 76.191 & 2.163 & 12.723 & 76.191 \\
\hline
\end{tabular}

Table 6: Rotated component matrix

\begin{tabular}{lccc}
\hline PSTRATS & \multicolumn{3}{c}{ Components } \\
\cline { 2 - 4 } & $\mathbf{1}$ & $\mathbf{2}$ & $\mathbf{3}$ \\
\hline Frequency & 0.613 & 0.263 & 0.177 \\
Duration & 0.572 & 0.370 & 0.195 \\
Location & 0.092 & 0.233 & 0.810 \\
Loudness & 0.163 & 0.473 & 0.009 \\
Belief regarding origin of voices & 0.274 & 0.100 & 0.779 \\
Amount of negative content & 0.056 & 0.879 & 0.179 \\
Degree of negative content & 0.113 & 0.901 & 0.179 \\
Amount of distress & 0.351 & 0.862 & 0.075 \\
Intensity of distress & 0.387 & 0.853 & 0.124 \\
Disruption to life caused by voices & 0.422 & 0.792 & 0.093 \\
Controllability of voices & 0.261 & 0.034 & 0.738 \\
Amount of preoccupation with delusion & 0.918 & 0.184 & 0.125 \\
Duration of preoccupation with delusion & 0.943 & 0.145 & 0.174 \\
Conviction & 0.914 & 0.146 & 0.205 \\
Amount of distress & 0.890 & 0.320 & 0.161 \\
Intensity of distress & 0.898 & 0.272 & 0.173 \\
Disruption to life caused by belief & 0.855 & 0.293 & 0.211 \\
\hline
\end{tabular}

*Extraction Method: Principal Component Analysis. Rotation Method: Varimax with Kaiser Normalization. a. Rotation converged in 5 iterations. Correlation cofficients (loadings) $>0.4$ are highlighted and bold.

\begin{tabular}{|c|c|c|c|}
\hline PANSS & $\begin{array}{c}\mathrm{F1} \\
\text { (Delusion) }\end{array}$ & $\begin{array}{c}\text { F2 } \\
\text { (Influence) }\end{array}$ & $\begin{array}{c}\text { F3 } \\
\text { (Externality) }\end{array}$ \\
\hline Positive Scale & $0.784^{*}$ & $0.471^{*}$ & $0.439^{*}$ \\
\hline Negative Scale & 0.015 & 0.028 & 0.1 \\
\hline General & $0.319^{*}$ & $0.323^{*}$ & 0.112 \\
\hline Psychopathology scale & & & \\
\hline Total & $0.603^{*}$ & $0.690^{*}$ & $0.919^{*}$ \\
\hline
\end{tabular}

\section{Amount of distress}

Majority of subject ascribed reality characteristics of their voices and so they are more distressing. 91\% patient reported distressing voices, $43 \%$ had majority (around $50 \%$ ) of voices distressing. $23 \%$ had all distressing voices. $9 \%$ had no distressing voices. Distress is also significantly correlated with other dimensions of AVH, like frequency, duration, belief, content.

\section{Disruption to life}

The voices of AVH may form an insistent background to life, so ensuring that a large part of patient's speech and behavior is occupied in answering and obeying the voices. The AVH described by patients are as real to them as any other remembered conversation and both real and auditory perception form the memories on which patients base their life and behavior in the present.

In this study $91 \%$ had effect of voices on life, $9 \%$ had complete disruption of daily life, unable to maintain daily activity, self-care and social relation.

\section{Controllability}

Hayashi et al. reported that uncontrollability of voices is significantly correlated with depression. ${ }^{17}$ Literature shows that about half of patient are able to exert some control over their voices. ${ }^{2}$ and two third developed the coping mechanism to deal with them. When various types of auditory input were presented to patient with schizophrenia who experienced hallucinations, it was found that it was not the degree of external stimulation that was required to diminish hallucination but the nature of stimulus and degree of attention it received. ${ }^{10}$ The mechanism used by patients with chronic schizophrenia to cope with persistent auditory hallucinations were discussed by Fallon and Talbot. ${ }^{21}$ High level of distress was found in patients who have little control and few means of coping.

This study is showing the significant positive correlation between controllability of voices and frequency, duration, location, belief regarding origin of voices, amount and intensity of distress and to disruption to life caused by voices. In this study 29\% patients have some control over voices, $71 \%$ had no control over voices. This difference in finding may be due to involvement of patients of Hospital for Mental Health (HMH) where most patients were chronic and resistant.

\section{Delusions}

Delusion associated with AVH may be responsible for unprovoked behavior disturbance. Literature shows that up to $90 \%$ of patients with hallucination also have delusions. ${ }^{22}$ Kulhara et al. found that delusion of persecution was the commonest, being present in $84.6 \%$ patients. ${ }^{23}$ They also found that the male patients had more delusions of persecution which was in agreement with the findings of Lucas et al. ${ }^{24}$ When perception is altered, illusions, hallucinations, and often delusion are experienced together. 
This study showed that $79 \%$ patients had delusion associated with AVH (mostly persecutory), $76 \%$ admitted that delusion affect their life, $29 \%$ had severe disruption to life so that hospitalization is usually necessary.

\section{Relation of AVH with other psychotic feature}

1. Relation with positive and negative scale of PANSS: Ninety six percent $(96 \%)$ patients with AVH had hallucinatory behavior, $85 \%$ had suspiciousness/ persecution, $46 \%$ had hostility, $93 \%$ had blunt affect. Bipolar index shows predominance of positive symptoms over negative symptoms (Bipolar index was positive in 61\% and negative in 35\%).

2. Relation with general psychopathology scale: Eighty percent $(80 \%)$ reported depressive features, $73 \%$ had anxiety, $35 \%$ had poor impulse control. It has been shown that as the time passages most of patients experience the decrease in frequency or change in nature of their hallucinations. ${ }^{11}$

\section{Correlation of various dimensions of $\mathrm{AVH}$}

Most of dimensions of AVH (of PSYRATS-AH) correlated well with each other with the following exceptions:

- Loudness was not significantly correlated with location of voices.

- Location of voices was not significantly correlated with controllability and belief regarding origin of voices.

- Amount of negative content of voices was not significantly correlated with controllability.

- Degree of negative content of voices was not significantly correlated with controllability of voices.

- Controllability of voices was not correlated with loudness and amount of negative content and degree of negative content.

There is vigorous debate about the presence of auditory verbal hallucination (AVH) in disorder other than psychoses such as borderline personality disorder and also in normal population. ${ }^{3}$ What remains to be answered is whether the form of these verbal hallucination is identical to the form of the verbal hallucination in schizophrenia for example.

\section{Factor structure of PSYRATS}

On principal component analysis with variance rotation for 17 items scale PSYRATS, yielded 3 broad factors (Eigen value more than 1) underlying the relationship among the participants responses to these items. These factors could be considered as three new hypothetical variables and can preserved for further studies. On the basis of nature of items included in factors they were named as delusional (F1), influence (F2), and externality (F3). Delusional factor (F1) having all delusional dimensions of PSYRATS scale with frequency of AVH and its effect on patient's life. The loading ranges from 0.943 to 0.422 and occupied $36.7 \%$ of total variance. F1 resembles F2(named as immersion in hallucination) of Singh et al. study which contains frequency, duration, constancy, overt behavior, time and affect characteristics of BPRS (Brief Psychiatric Rating Scale). ${ }^{4}$

Factor 2 in this study named as influence as it having negative content of AVH with its severity, distress, and its effect on patient's life. This factor has similarity with F3 of Hayashi et al. study. ${ }^{17}$ The loading range is from 0.473 to 0.901 with $26.7 \%$ of total variability. Factor three (F3) named as externality as it is mainly denoting external things like location of voices, origin of voices (internal/external) and patient's ability to control them (similarity to Hayashi et al. study). ${ }^{17}$ The loading range 0.738 to 0.810 with 12.7 $\%$ occupancy of total variance.

In study done by Singh et al. five eigen values greater than unity was obtained, however on analyzing scree plot two factors was obtained (same as in our study). First named as reality of hallucinatory perception, second as immersion in hallucination. Both factors were observed to have positive correlation with BPRS (Brief Psychiatric Rating Scale). ${ }^{4}$ In our both F1 (delusion) and F2 (influence) have positive correlation with total PANSS, positive and negative subscale. F3 (externality) have positive correlation with positive subscale and total PANSS. None of three factors has correlation with negative scale [Table 7].

\section{Limitations of this study}

1. Duration of schizophrenia spectrum psychoses and AVH was not included.

2. Less number of phenomenological dimensions.

\section{CONCLUSION}

Patients with schizophrenia spectrum disorders having auditory hallucinations attending psychiatry department of medical school affiliated general hospital in Western India were interviewed for studying the phenomenological features.

All patients were interviewed using PSYRATS which was followed by administration of PANSS. Majority of patients were schizophrenic (82\%), $79 \%$ patients had delusion. $72 \%$ admitted that voices were coming from outside, $71 \%$ had no control over them. 19\% reported voices threat to harm self, extreme instructions or command to harm self or others. Majority of patient $(96 \%)$ had hallucinatory behavior with predominance of positive symptoms. Majority of dimensions of PSYRATS were also correlated to each other. On principal component analysis there are three factors with Eigenvalue more than 
one in PSYRATS with $76 \%$ of total variance. But on scree plot two main factors were found. F1 and F2 both have positive correlation with total PANSS, positive and general psychopathology. None of three is correlated to negative subscale of PANSS.

\section{ACKNOWLEDGEMENT}

I am thankful to all patients and their caregivers who participated in study.

\section{REFERENCES}

1. Drake R, Haddock G, Tarrier N, Bentall R and Lewis S. The psychotic symptom rating scales (PSYRATS): Their usefulness and properties in first episode psychosis. Schizophr Res. 2007; 89:119-122. https://doi.org/10.1016/j.schres.2006.04.024

2. Nayani TH and David AS. Auditory hallucination: Phenomenological survey. Psychol Med. 1996; 26 (1):177-189. https://doi.org/10.1017/S003329170003381X

3. McCarthy Jones S, Trauer T, Mackinnon A, Sims E, Thomas N and Copolov DL. A new phenomenological survey of auditory hallucinations: evidence for subtypes and implications for theory and practice. Schizophr Bull. 2014;40:231-235.

https://doi.org/10.1093/schbul/sbs156

4. Singh G, Sharan $P$ and Kulhara P. Phenomenology of hallucinations: a factor analytic approach. Psychiatry Clin Neurosci. 2003; 57:333-336.

https://doi.org/10.1046/j.1440-1819.2003.01125.x

5. American Psychiatric Association. Diagnostic and Statistical Manual of Mental Disorder, $4^{\text {th }}$ ed, TR. Washington, DC: American Psychiatric publishing;2000.

6. Haddock G, McCarron J, Tarrier N and Faragher EB. Scales to measure dimensions of hallucinations and delusions: the psychotic symptom rating scales (PSYRATS). Psychol Med 1999; 29:879-889.

https://doi.org/10.1017/S0033291799008661

7. Kay SR, Fiszbein A and Opler LA. The Positive And Negative Syndrome Scale (PANSS) for schizophrenia. Schizophr Bull. 1987;13(2):261-276.

https://doi.org/10.1093/schbul/13.2.261

8. Kay SR, Opler LA and Lindemayer JP. Reliability and validity of positive and negative syndrome scale for psychotics. Psychiatry Res. 1988; 23(1):99-110.

https://doi.org/10.1016/0165-1781(88)90038-8

9. $\quad$ SPSS for Windows. Chicago: SPSS Inc; 1996. Rel 7.5.1.
10. Femi Oyebode. Sims's Symptoms in the Mind:Textbook of Descriptive Psychopathology. $5^{\text {th }}$ ed.Saunders: Elsevier Publisher;2008.

11. Lewis S, Escalona PR and Keith SJ. 12.2 Phenomenology of Schizophrenia. In: Sadock B.J, Sadock V.A, Ruiz P. editors. Kaplan And Sadock's Comprehensive Textbook Of Psychiatry. 9th ed. Baltimore, William and Wilkins; 2009, pp1433-40..

12. Junginger $\mathrm{J}$. command hallucinations and prediction of dangerousness. Psychiatr Serv. 1995; 46(9):911-914. https://doi.org/10.1176/ps.46.9.911

13. Almeida O, Forstal $H$, Howard $R$ and David A.S: Unilateral auditory hallucination. Br J Psychiatry. 1993; 162:262-264 https://doi.org/10.1192/bjp.162.2.262

14. Taylor $P$ and Fleminger $J$. The lateralization of symptoms in schizophrenia. Br J Psychiatry. 1981: 54, 59-65. https://doi.org/10.1111/j.2044-8341.1981.tb01470.x

15. Ramanathan A, Palamiappan $\vee$ and Somsundaram $O$. Experienced reality of auditory hallucinations in schizophrenia. Indian J Psychiatry 1981; 24:44-52. https://doi.org/10.1177/0975156419810102

16. Remington $A$ and Larkin $M N$. Form and content of schizophrenia hallucinations. Am J Psychiatry. 1979;136, 940-943. https://doi.org/10.1176/ajp.136.7.940

17. Hayashi N, Igarashi Y, Suda Kand Nakagawa S. Phenomenological features of auditory hallucinations and their symptomatological relevance. Psychiatry Clin Neurosci. 2004; 58:651-659. https://doi.org/10.1111/j.1440-1819.2004.01316.x

18. Hellerstein D, Frosch $W$ and Koenigsberg HW. The clinical significance of command hallucinations. Acta Psychiatr Scand. 1995; 92:97-102. https://doi.org/10.1111/j.1600-0447.1995.tb09550.x

19. Goodwin FK and Jamison KR. Manic-Depressive Illness: Bipolar Disorders and Recurrent Depression. $2^{\text {nd }}$ edition. New York: Oxford University Press; 1979.

20. Zisook S, Byrd D, Kuck J and Jeste DV. Command hallucinations in outpatients with schizophrenia. J Clin Psychiatry. 1995; 56: 462-465.

21. Falloon IRH and Talbot RE. Persistent auditory hallucinations: coping mechanism and implications for management. Psychol Med.1981; 11:329-339. https://doi.org/10.1017/S0033291700052144

22. Yager J and Gitlin M.J. In: Friedman, Kaplan and Kaplan editors. Comprehensive Textbook of Psychiatry (CTP). 6th ed. Baltimore, William and Wilkins; 1995.Chapter 10.1. pp 654-655.

23. Kulhara $P$, Mattoo SK, Awasthi $A$ and Chandiramani $K$. Psychiatric manifestations of Categoclass+ schizophrenia. Indian J Psychiatry. 1987; 29:307-313.

24. Lucas CJ, Sainsbury P and Collins JG. A social and clinical study of delusions in schizophrenia. J Ment Sci. 1962; 108:747-758. https://doi.org/10.1192/bjp.108.457.747

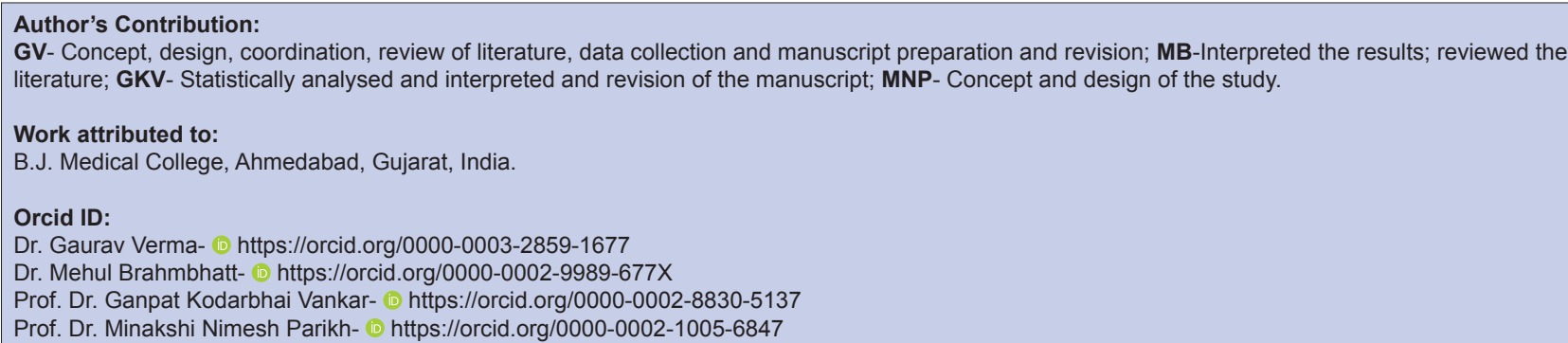

